\title{
The Effect of On-line Product Presentation : A Comparative Study between 3D and General Product Presentation
}

\author{
Shuo liu* \\ Received: June 28, 2017. Revised: August 28, 2017. Accepted: October 15, 2017.
}

\section{Abstract}

Purpose - This research aims to examine the effects of $3 \mathrm{D}$ online products presentation by comparing it with general presentation.

Research design, data, and methodology - To rigorously investigate the differences of effects between 3D presentation and general presentation, this study examines the differences of the two presentations in vividness, informedness, entertainment, product trust, and purchase intention. This research designed two different forms of online product presentations, 3D and general presentation for an experiment.

Results - The research findings indicate that 1) the vividness of online product presentation has a positive impact on the informedness and entertainment. While both vividness and informedness product presentation have a positive impact on product trust, the entertainment of online product presentation has no significant impact. 2) Vividness, informedness, entertainment, product trust, and purchasing intention showed significant differences between 3D and general product presentations. 3) Overall, 3D product presentation showed a stronger impact on purchasing intention than the general product presentation.

Conclusions - This research expands the area of business presentation by comparing the differences of 3D and general presentation methods. This study made a great contribution to theory development, and also to guidelines for practice. These insights could be used by organizations in developing realistic environments for business presentations.

Keywords: 3D Presentation, Vividness, Entertainment, Informedness, Product Trust, Purchase Intention, Comparison.

JEL Classifications: M31, M37.

\section{Introduction}

With the rapid growing popularity of Internet service, online product presentation as a new form of advertising has been widely exploited by organizations. Product presentation plays a critical role in designing an effective and efficient transaction process. Since the late 1990's, "image-text-3D environment -Digital display," going beyond text-based mechanism, has been widely used.

The main objective of this research is to examine the effects of $3 \mathrm{D}$ online products presentation, by comparing with general presentation. To rigorously investigate the differences of effects between 3D online products presentation and general presentation, this research examines the differences

* School of Economics \& management, Shandong Yingcai University, China. Tel: +86-156-6582-9765, E-mail: bluelove87@163.com of the two presentations in vividness, informedness, entertainment, product trust, and purchase intention. This research designed two different forms of online product presentations, 3D and general presentation for an experiment. With the designed two forms of presentations, this study collected a total of 215 survey responses who viewed both presentations.

\section{Theory}

Jarvenpaa and Todd (1997) found that product awareness is a significant element for consumer attitudes and purchase intentions, and is important for the online purchase process. Different forms of product presentation will have an impact on the attitude of consumers using the network (Daugherty et al., 2008), and also decide whether to drive the purchase 
intention (Park et al., 2005). At present, in the e-commerce environment, the research of product display type can be divided into four categories. Reduct as <Table 1>

$<$ Table 1> Research of product display type

\begin{tabular}{|c|c|}
\hline Research directions & Researchers \\
\hline Table \& Graph & $\begin{array}{l}\text { Remus (1984); Jarvenpaa \& Dickson } \\
\text { (1988) }\end{array}$ \\
\hline Visual \& Text & Chau et al. 2000; Park et al. (2005) \\
\hline $\begin{array}{l}\text { Picture ( have or } \\
\text { not ) \& Paragraph }\end{array}$ & Blanco, Sarasa, \& Sanclemente (2010) \\
\hline $3 \mathrm{D}$ virtual & $\begin{array}{l}\text { Li Daughterty \& Biocca (2002); } \\
\text { Park, Stoel, \& Lennon (2005) }\end{array}$ \\
\hline
\end{tabular}

According to the characteristics of type differences of product presentation and the diversification of users, effective product presentation form can deliver effective, emotional information of product to make users easy access to information while promoting consumption (Chau et al., 2000). When consuming on the internet, consumers may encounter some problems in the process of choosing products, like when receiving the product, they feel that is different from the information they obtain from the Internet, therefore resulting in return of goods. In order to overcome this problem, the application of virtual technology to display the good characterized by 3D effects emerges. 3D product presentation is a new form of advertisement to simulate the actual goods with the application of three dimensional image technologies to allow consumers to better observe the goods before buying. 3D product presentation simulates the physical state of visual auditory and behavioral experience to allow consumers to better experience the goods. Previous studies have shown that in on-line environment, providing virtual image and indirect experience to customers before purchasing can make them acquire information similar to the physical store (Li et al., 2002). Using 3d product presentation enables the customers to directly observe the appearance characteristics of the product, and while to decide how to observe product.

\section{Model \& Hypothesis}

Ducoffe (1996) conducted an experiment with individual advertising as the subjective judgment. The study showed that the informedness, entertainment and irritation of advertising had some effect on the value and attitude of the advertisement, and then the advertising attitude model was put forward. According to his research, the irritation has a high impact on the entertainment, and also has an impact on the accuracy of the statistical data and the analysis results (Thompson,1997). Therefore, this study uses two attribute variables out of the Ducoffe advertising attitude model, namely, informedness and entertainment, and then add the visualization provided by the product as a new variable. Using effect of online product presentation on those variables, and the influencing relationship among those variables, product trust, purchasing intention builds the research model. <Figure $1>$ is the research model constructed by the research according to the above content.

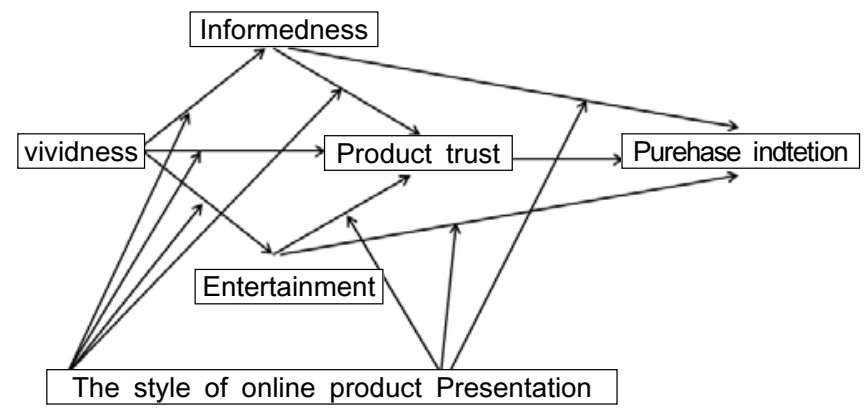

<Figure 1> Research Model

\subsection{Different hypothesis between general and 3D}

The impact of general product presentation and 3D product presentation is different

Consumers cannot get the same product experience in the online environment as in the actual store, hence can only get an indirect product experience. But the new technology of visual image can overcome the problem that consumers cannot experience feeling and touching in virtual store (Wagner, 2005). Virtual experience is a type of indirect experience. Consumers can conduct stimulation technology, such as move, expansion, reduction, experiencing the same feeling as real product ( $\mathrm{Li}$, Daugherty, \& Biocca, 2002). According to the research of this scholar, compared with the normal Internet experience, virtual experience is more vividly cognitive. Therefore, the product for the display of these attributes on the product trust, the purchase of the intention of the impact of general product presentation and $3 \mathrm{~d}$ product presentation is different. Therefore, we make the following hypothesis.

$<\mathrm{H} 1>$ These attributes of product presentation on the product trust, the purchase intention of the impact of general product presentation and 3D product presentation is different.

$<\mathrm{H} 1-1>$ The Vividness of the impact of general product presentation and 3Dproduct presentation is different

$<\mathrm{H} 1-2>$ The informedness of the impact of general product presentation and 3D product presentation is different.

$<\mathrm{H} 1-3>$ The entertainment of the impact of general product presentation and 3D product presentation is different.

$<\mathrm{H} 1-4>$ The product trust of the impact of general product 
presentation and 3D product presentation is different.

\subsection{Hypothesis by these attributes}

The influencing relationship among the attributes of the product presentation, product trust and purchase intention

Some research has verified the important factors to influence the visual online consumption, which can increase the degree of goodwill of consumers to the purchases, improve the purchasing desire (Coyle \& Thorson, 2001). Carson, Peck, Chiders (1996) argue that providing more relevant informedness in the online consumer environment will increase the likelihood of purchasing. Looking at some advertising literature, happy ads can make people get a positive feeling that can improve the success of transaction (Alwitt \& Prabhaker, 1994). Advertising-induced entertainment has an important effect on consumer awareness of advertising (Shavitt, Lowrey, \& Haefner, 1998). Therefore, we make the following hypothesis.

$<\mathrm{H} 2-1>$ The vividness of product presentation have positive impact on the informedness

$<\mathrm{H} 2-2>$ The vividness of product presentation have positive impact on the entertainment

$<\mathrm{H} 2-3>$ The vividness of product presentation have positive impact on the product trust

$<\mathrm{H} 2-4>$ The informedness of product presentation have positive impact on the product trust

$<\mathrm{H} 2-5>$ The informedness of product presentation have positive impact on the purchase intention

$<\mathrm{H} 2-6>$ The entertainment of product presentation have positive impact on the product trust.

$<\mathrm{H} 2-7>$ The entertainment of product presentation have positive impact on the purchase intention.

$<\mathrm{H} 2-8>$ The product trust of product presentation have positive impact on the purchase intention.

$<\mathrm{H} 3>$ For different types of products shows, the impact of its attributes for the product trust and the purchase intention is different.

$<\mathrm{H} 3-1>$ The vividness of 3D product presentation have positive impact on the informedness is better than the general product presentation's

$<\mathrm{H} 3-2>$ The vividness of 3D product presentation have positive impact on the entertainment is better than the general product presentation's

$<\mathrm{H} 3-3>$ The vividness of 3D product presentation have positive impact on product trust is better than the general product presentation's

$<\mathrm{H} 3-4>$ The informedness of 3D product presentation have positive impact on product trust is better than the general product presentation's

$<\mathrm{H} 3-5>$ The informedness of 3D product presentation have positive impact on purchase intention is better than the general product presentation's

$<$ 33-6> The entertainment of 3D product presentation have positive impact on product trust is better than the general product presentation's

$<\mathrm{H} 3-7>$ The entertainment of 3D product presentation have positive impact on purchase intention is better than the general product presentation's

This article selects the latest DSLR camera as an example of a product presentation. The same products are provided with $3 \mathrm{~d}$ and the general presentation forms, of which the experiments are carried out.

\section{Analysis}

\subsection{Reliability analysis}

The internal compatibility is determined with application of Chronbach Alpha coefficient in the general reliability analysis. When the Cronbach score is greater than 0.7 , the gauge has a higher reliability. <Table 2> shows that the Cronbach's a value is between 0.821 and 0.901 , hence the validity of the reliability can be determined.

<Table 2> Reliability
\begin{tabular}{|c|c|}
\hline Variable & Cronbach's Alpha \\
\hline Vividness & 0.872 \\
\hline Entertainment & 0.901 \\
\hline Informedness & 0.841 \\
\hline Product trust & 0.821 \\
\hline Purchase intention & 0.882 \\
\hline
\end{tabular}

\subsection{Validity analysis}

The validity of this paper adopts the bootstrap method of PLS to verify the factor loading value of the constituent concept. The recommended value of factor loading in the measurement item is greater than 0.7 and the average variation extraction criterion is that the value of $A V E$ is greater than 0.5 (Fornell \& Larcker, 1981). The factor loading values of each path in this paper are shown in the following <Table $3>$. The value of the factor loading is greater than 0.7 , and the factor loading value of the variable is larger than the value of cross factor, and the AVE value is more than 0.5 , hence the validity of the content is proved. 
<Table 3> Factor Analysis

\begin{tabular}{|c|c|c|c|c|c|}
\hline & Vividness & Informedness & Entertainment & Product trust & Purchase intention \\
\hline Vividness1 & 0.745 & 0.430 & 0.417 & 0.322 & 0.401 \\
\hline Vividness2 & 0.793 & 0.331 & 0.547 & 0.253 & 0.321 \\
\hline Vividness3 & 0.861 & 0.485 & 0.537 & 0.391 & 0.430 \\
\hline Vividness4 & 0.812 & 0.361 & 0.528 & 0.331 & 0.342 \\
\hline Vividness5 & 0.851 & 0.379 & 0.589 & 0.503 & 0.513 \\
\hline Informedness1 & 0.359 & 0.796 & 0.397 & 0.301 & 0.356 \\
\hline Informedness2 & 0.400 & 0.793 & 0.348 & 0.343 & 0.396 \\
\hline Informedness3 & 0.421 & 0.778 & 0.332 & 0.375 & 0.406 \\
\hline Informedness4 & 0.354 & 0.762 & 0.449 & 0.404 & 0.410 \\
\hline Informedness5 & 0.371 & 0.777 & 0.440 & 0.283 & 0.335 \\
\hline Entertainment1 & 0.528 & 0.462 & 0.883 & 0.462 & 0.519 \\
\hline Entertainment2 & 0.598 & 0.360 & 0.846 & 0.397 & 0.420 \\
\hline Entertainment3 & 0.610 & 0.493 & 0.903 & 0.397 & 0.468 \\
\hline Entertainment4 & 0.534 & 0.444 & 0.881 & 0.375 & 0.485 \\
\hline Product trust1 & 0.396 & 0.398 & 0.393 & 0.851 & 0.567 \\
\hline Product trust2 & 0.285 & 0.277 & 0.358 & 0.792 & 0.448 \\
\hline Product trust3 & 0.419 & 0.381 & 0.344 & 0.737 & 0.423 \\
\hline Product trust4 & 0.346 & 0.358 & 0.403 & 0.845 & 0.471 \\
\hline Purchase intention1 & 0.451 & 0.377 & 0.471 & 0.501 & 0.848 \\
\hline Purchase intention2 & 0.431 & 0.457 & 0.459 & 0.543 & 0.884 \\
\hline Purchase intention3 & 0.458 & 0.506 & 0.466 & 0.470 & 0.872 \\
\hline Purchase intention4 & 0.375 & 0.343 & 0.458 & 0.535 & 0.833 \\
\hline
\end{tabular}

$<$ Table 4> Variable correlation coefficient \& AVE

\begin{tabular}{|c|c|c|c|c|c|c|}
\hline & AVE & Vividness & Informedness & Entertainment & Product trust & Purchase intention \\
\hline Vividness & 0.662 & 0.814 & & & & \\
\hline Informedness & 0.610 & 0.489 & 0.781 & & & \\
\hline Entertainment & 0.772 & 0.646 & 0.501 & 0.878 & & \\
\hline Product trust & 0.652 & 0.450 & 0.441 & 0.465 & 0.808 & \\
\hline Purchase intention & 0.740 & 0.499 & 0.490 & 0.539 & 0.596 & 0.860 \\
\hline
\end{tabular}

* Diagonal: root square AVE,

** Off-diagonal: related coefficient (** 0.05 is Significance)

$<$ Table 5> Groups statistics

\begin{tabular}{|c|c|c|c|c|c|}
\hline & Group & $\mathbf{N}$ & Mean & Std. Deviation & Std. Error Mean \\
\hline \multirow{2}{*}{ Vividness } & general & 109 & 3.171 & .502 & .048 \\
\cline { 2 - 6 } & 3D & 106 & 3.939 & .488 & .047 \\
\hline \multirow{2}{*}{ Informedness } & general & 109 & 3.382 & .420 & .040 \\
\cline { 2 - 6 } & 3D & 106 & 4.043 & .413 & .040 \\
\hline \multirow{2}{*}{ Entertainment } & general & 109 & 3.011 & .502 & .048 \\
\cline { 2 - 6 } & 3D & 106 & 3.837 & .549 & .053 \\
\hline \multirow{2}{*}{ Product trust } & general & 109 & 3.404 & .526 & .050 \\
\cline { 2 - 6 } & 3D & 106 & 3.8494 & .486 & .047 \\
\hline \multirow{2}{*}{ Purchase intention } & general & 109 & 3.262 & .552 & .053 \\
\cline { 2 - 6 } & 3D & 106 & 3.892 & .489 & .048 \\
\hline
\end{tabular}

\subsection{Difference effect analysis \& hypothesis verification}

In this paper, we use SPSS18.0 to compare the difference between the 3D presentation and the general presentation, and use PLS to verify the difference between the two. After determining the reliability and validity of the variables, it is necessary to verify the difference between the 3D presentation and the general presentation. An independent sample of two populations was tested using spss18.0.As the <Table 5>.

Notice of observation of $t$ test, two groups of vividness, informedness, entertainment, product trust, purchase intention of $p=0.000 \quad(p<0.05)$, so the general presentation and $3 D$ presentation groups have significant difference between the average value and standard value, so that hypothesis $1(<\mathrm{H} 1-1>-<\mathrm{H} 1-5>)$ is established as $<$ Table $6>$. 
$<$ Table 6> T test

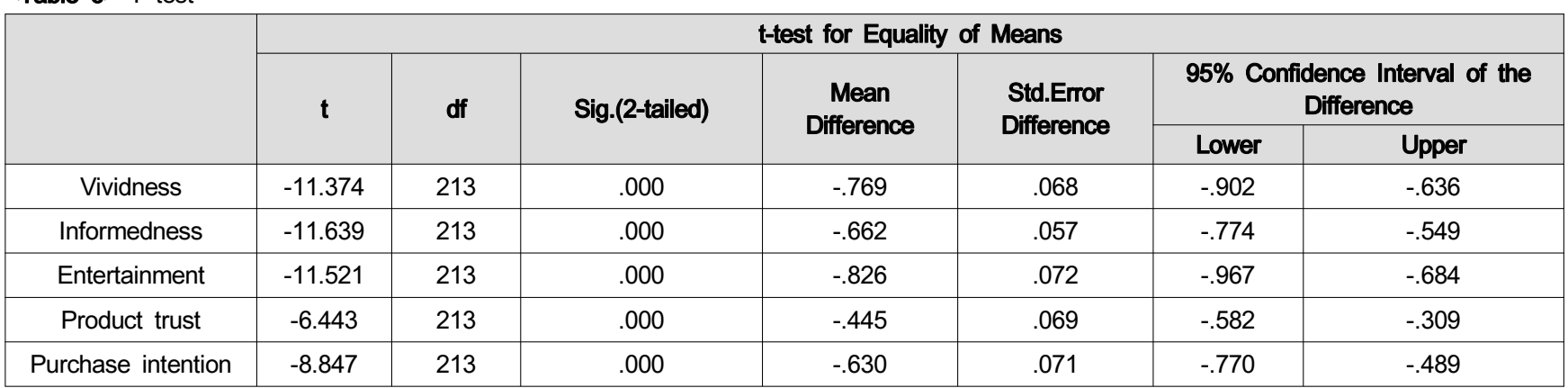

$<$ Table $7>$ The results of the hypothesis

\begin{tabular}{|l|c|c|c|c|c|c|}
\hline & $\begin{array}{c}\text { Original } \\
\text { sample }\end{array}$ & $\begin{array}{c}\text { Sample } \\
\text { mean }\end{array}$ & $\begin{array}{c}\text { Standard } \\
\text { error }\end{array}$ & Path coefficient & T value & Result \\
\hline H2-1: Vividness $\rightarrow$ Informedness & 0.465 & 0.473 & 0.078 & 0.465 & 5.939 & Accepted \\
\hline H2-2: Vividness $\rightarrow$ Entertainment & 0.215 & 0.217 & 0.102 & 0.215 & 2.108 & Accepted \\
\hline H2-3: Vividness $\rightarrow$ Product trust & 0.620 & 0.629 & 0.065 & 0.620 & 9.485 & Accepted \\
\hline H2-4: Informedness $\rightarrow$ Product trust & 0.238 & 0.231 & 0.094 & 0.438 & 2.532 & Accepted \\
\hline H2-5: Informedness $\rightarrow$ Purchase intention & 0.253 & 0.264 & 0.081 & 0.235 & 3.134 & Accepted \\
\hline H2-6: Entertainment $\rightarrow$ Product trust & 0.199 & 0.202 & 0.115 & 0.199 & 1.725 & Reject \\
\hline H2-7: Entertainment $\rightarrow$ Purchase intention & 0.211 & 0.204 & 0.092 & 0.219 & 2.290 & Accepted \\
\hline H2-8: Entertainment $\rightarrow$ Purchase intention & 0.322 & 0.315 & 0.093 & 0.522 & 3.467 & Accepted \\
\hline
\end{tabular}

\subsection{All path analysis and hypothesis verification}

The variance of the path in the PLS analysis is expressed by the R-squared value in the explanatory variance (Chin \& Gopal, 1995). As for the analysis results of PLS, informedeness and entertainment values respectively accounts for $21.6 \%$ and $38.5 \%$, the product trust value is $29.2 \%$, interpretation value of product trust and the former variable to the purchase intention is $40.1 \%$, and all these value are more than the appropriate measured value $10 \%$ proposed by Falk and Miller (1992). Through the path analysis among groups, we use Bootstrap of SmartPLS to conduct verification of the hypothesis among variables. Based on the Bootstrapping calculation, the statistical significance of the structural model is based on the $t$ statistic. Under the $5 \%$ confidence level, if the $t$ value is greater than the critical value of 1.96 , the path coefficient is significant. The results of the study are shown below $<$ Figure 2>.

As the vividness, from the verification results of hypothesis $\langle\mathrm{H} 2-1\rangle,\langle\mathrm{H} 2-2\rangle$ and $\langle\mathrm{H} 2-3\rangle$ about the positive impact of visuality on informedness, entertainment, and product trust, coefficient of each path is $0.465,0.620,0.215$, and each of $\mathrm{T}$ value is $5.939,9.485,2.108$. So $\langle\mathrm{H} 2-1\rangle$, $<\mathrm{H} 2-2>$ and $<\mathrm{H} 2-3>$ are established.

As the informedness, from the verification results of hypothesis $<\mathrm{H} 2-4>$ and $<\mathrm{H} 2-5>$ about the positive impact of informedness on product trust and purchase intention, coefficient of each path is 0.438, 0.235, and each of $\mathrm{T}$ value is $2.532,3.134$,. So, $\langle\mathrm{H} 2-4\rangle$ and $\langle\mathrm{H} 2-5\rangle$ are established.

As the entertainment, from the verification results of hypothesis $<\mathrm{H} 2-6>$ and $<\mathrm{H} 2-7>$ about the positive impact of entertainment on product trust and purchase intention, coefficient of each path is 0.199, 0.299, and each of $\mathrm{T}$ value is $1.725,2.290$, So, $\langle\mathrm{H} 2-6\rangle$ is dismissed and $\langle\mathrm{H} 2-7\rangle$ is established.

As the product trust, from the verification results of hypothesis <H2-8> about the positive impact of purchase intention, coefficient of each path is 0.522 and $\mathrm{T}$ value is 3.467 ,. So $<\mathrm{H} 2-8>$ is established

The results of the hypothesis are shown below <Table $7>$.

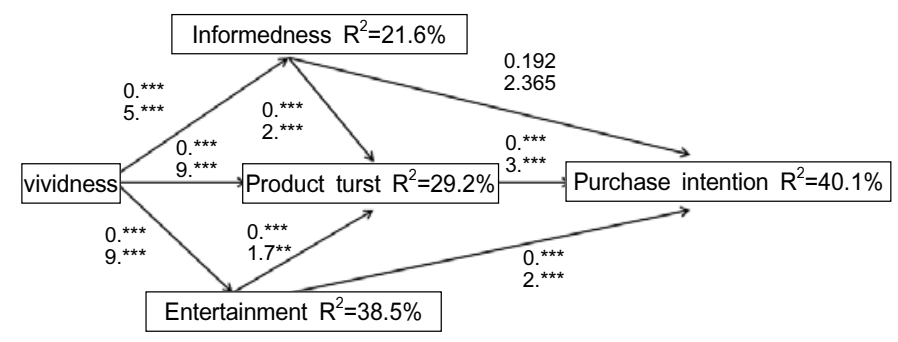

<Figure 2> The result of group's path coefficient - 
$<$ Table $8>$ A comparison of $3 \mathrm{D}$ and the general presentation

\begin{tabular}{|c|c|c|c|c|c|c|c|}
\hline & \multicolumn{2}{|c|}{ 3D presentation } & \multicolumn{2}{|c|}{ General presentation } & \multicolumn{2}{|c|}{ Difference } & \multirow[b]{2}{*}{ Result } \\
\hline & $\begin{array}{c}\text { path } \\
\text { coefficient }\end{array}$ & $\mathrm{T}$ value & $\begin{array}{c}\text { path } \\
\text { coefficient }\end{array}$ & $\mathrm{T}$ value & $\begin{array}{l}\text { coefficient } \\
\text { difference }\end{array}$ & $\mathrm{T}$ value & \\
\hline $\begin{array}{c}\mathrm{H} 3-1 \\
\text { Vividness } \rightarrow \text { Informedness }\end{array}$ & 0.390 & 4.488 & 0.074 & 0.525 & 0.316 & 19.671 & Supported \\
\hline $\begin{array}{c}\mathrm{H} 3-2 \\
\text { Vividness } \rightarrow \text { Entertainment }\end{array}$ & 0.408 & 4.389 & 0.333 & 3.430 & 0.075 & 5.780 & Supported \\
\hline $\begin{array}{c}\mathrm{H} 3-3 \\
\text { Vividness } \rightarrow \text { Product trust }\end{array}$ & 0.195 & 2.040 & -0.115 & 1.117 & 0.08 & 5.915 & Supported \\
\hline $\begin{array}{c}\mathrm{H} 3-4 \\
\text { Informedness } \rightarrow \text { Product trust }\end{array}$ & 0.228 & 2.158 & 0.091 & 0.970 & 0.137 & 15.381 & Supported \\
\hline $\begin{array}{c}\text { H3-5 } \\
\text { Informedness } \rightarrow \text { Purchase intention }\end{array}$ & 0.316 & 3.442 & 0.192 & 2.365 & 0.124 & 10.493 & Supported \\
\hline $\begin{array}{c}\mathrm{H} 3-6 \\
\text { Entertainment } \rightarrow \text { Product trust }\end{array}$ & 0.108 & 1.532 & 0.353 & 3.272 & -0.245 & 16.126 & not supported \\
\hline $\begin{array}{c}\mathrm{H} 3-7 \\
\text { Entertainment } \rightarrow \text { Purchase intention }\end{array}$ & 0.139 & 1.965 & 0.109 & 1.214 & 0.030 & 2.296 & Supported \\
\hline
\end{tabular}

\subsection{Path analysis and hypothesis verification between two groups}

This article is divided into $3 \mathrm{D}$ presentation group and the general presentation group, there are 106 samples in 3D group, and there are 109 samples in general group.

The significant difference verification is conducted between two groups in 3D presentation and general presentation (the $\mathrm{T}$ value of the difference path coefficients). At the $5 \%$ confidence level, if the $t$ value is greater than the critical value of 1.96, the path coefficient is significant. Teo and Yeong (2003) used the following formula to analyze the differences between the path coefficients and the standard error.

$$
\begin{gathered}
S E=\sqrt{\frac{(N-1) \times S E 1^{2}+(M-1) \times S E 2^{2}}{N+M-2}} \times \sqrt{\frac{1}{N}+\frac{1}{M}} \\
T(\min u s)=\frac{P_{n}-P_{m}}{S E}
\end{gathered}
$$

Where " $n$ " is the number of samples for the first population, " $m$ " is the number of samples for the second population, "SE1" is the standard error for the first population sample, "SE2" is the standard error for the second population sample, "Pn" is the first population The path coefficient, "Pm", is the second group path coefficient.

This paper is a comparative analysis of the influence of vividness on informedness, entertainment, product trust, information and entertainment on product trust and purchase intention in 3D presentation and general presentation. The validation of the type difference is the judgment of the difference between the $3 \mathrm{D}$ and the general group. The results of the analysis are shown in <Table $8>$ the vividness impact on informedness, entertainment, product trust, informedness on product trust, purchase intention, entertainment impact on purchase intention, 3D presentation model shows better results than general presentation, which is verified. But the impact of entertainment on product trust in the general shows gets better results than shown in the 3D presentation model. Therefore, $\langle\mathrm{H} 3-1\rangle-<\mathrm{H} 3-5\rangle$ and $<\mathrm{H} 3-7>$ are supported. However, $<\mathrm{H} 3-6>$ is not supported.

\section{Conclusion}

The research findings indicate that 1) the vividness of online product presentation has a positive impact on the informedness and entertainment. While both vividness and informedness product presentation have a positive impact on product trust, the entertainment of online product presentation has no significant impact. 2) Vividness, informedness, entertainment, product trust, and purchasing intention showed significant difference between 3D and general product presentations. 3) Overall, 3D product presentation showed a stronger impact on purchasing intention than the general product presentation did.

In conclusion, this research expands in the area of business presentation by comparing the differences $3 \mathrm{D}$ and general presentation method. This study made a great contribution to theory development, but also to guidelines for practice. These insights could be used by organizations in developing realistic environments for business presentation.

\section{Limitation}

This research is an analysis of the overall effect of online 
product presentation; especially comparing the effect between 3D and general presentation. But due to the limitation of time and space, it's difficult to conduct a large-scale questionnaire survey. So we can only select the students who have better popularity and accept new things as a reference object. Thus, the survey was not comprehensive.

There are many factors influencing the effect of online

\section{References}

Alwitt, L. F., \& Prabhaker, P. R. (1994). Identifying Who Dislikes Television: Not By Demographics Alone. Journal of Advertising Research, 34(6), 17-29.

Carson, S. J., Joann, J. P., \& Terry, L. C. (1996). Preliminary Results on the Determinants of Technology Assisted Shopping(TAS): A Model, Measure Development, and Validation. Proceedings of AMA Educator's Conference, American Marketing Association, Winter, 229-239.

Chau, P. Y. K., Au, G., \& Tam, K. Y. (2000). Impact of Information Presentation Modes on Online Shopping: an Empirical Evaluation of a Broadband Interactive Shopping Service. Journal of Organizational Computing and Electronic Commerce, 10(1), 1-22.

Chin, W. W., \& Gopal, A. (1995). Adoption Intention in GSS: Importance of Beliefs. Data Base Adv., 26, 42-64.

Coyle, J. R., \& Thorson, E. (2001). The Effects of Progressive Levels of Interactivity and Vividness in Web Marketing Sites. Journal of Advertising, 30(3), 65-77.

Daugherty, T., Li, H., \& Biocca, F. (2008). Consumer Learning and the Effects of Virtual Experience Relative to Indirect and Direct Product Experience. Psychology and Marketing, 25(7), 568-86.

Flavián-Blanco, C., Gurrea-Sarasa, R., \& OrúsSanclemente, C. (2010). Effects of Visual and Textual Information in Online Product Presentations: Looking for the Best Combination in Website Design. European Journal of Information Systems, 19(6), 668-686.

Fornell, C., \& Larcker, D. (1981). Evaluating Structural Equation Models with Unobservable Variables and product presentation. This research, from the perspective of consumer experience, selects vividness, informedness, entertainment and other factors to carry on the research. However, other elements of presentation are not included. For example, product events, product elements, product contents and so on. Future research should be considered in terms of product (price, quality) and other factors (event, indirect effects).

Measurement Error. Journal of Marketing Research, 18(1), 39-50.

Jarvenpaa, S. L., \& Dickson, G. W. (1988). Graphics and Managerial Decision Making: Research-based Guidelines. Communications of the ACM, 31(6), 764 -774 .

Jarvenpaa, S. L., \& Todd, P. A. (1997). Consumer Reactions to Electronic Shopping on the World Wide Web. International Journal of Electronic Commerce, 1(2), 59-88.

Li, H., Daugherty, T., \& Biocca, F. (2002). Impact of 3-D Advertising on Product Knowledge, Brand Attitude, and Purchase Intention: The Mediating Role of Presence. Journal of Advertising, 31(3), 43-57.

Park, J. H., Lennon S. J., \& Stoel, L. (2005). Online Product Presentation: Effects on Mood, Perceived Risk, and Purchase Intention. Psychology and Marketing, 22(9), 695-719.

Remus, W. (1984). A Study of Graphical and Tabular Display and Their Interaction with Environmental Complexity. Management Science, 33, 1200-1204.

Shavitt, S., Lowrey, P., \& Haefner, J. (1998). Public Attitudes Towards Advertising: More Favourable Than You Might Think. Journal of Advertising Research, 38(4), 7-22.

Teo, T. S. H., \& Yeong, Y. D. (2003). Assessing the Customer Decision Process in the Digital Marketplace. Omega, 31(5), 349-363.

Thompson, B. (1997). The Importance of Structure Coefficients in Structural Equation Modeling Confirmatory Factor Analysis. Educational and Psychological Measurement, 57(1), 5-19.

Wagner. (2005). A Robustness and Evolvability in Living Systems. NJ: Princeton University Press. 